\title{
LIMITED INFLUENCE OF THE MESOTHELIUM ON THE INFLUX OF MONOCYTES INTO THE PERITONEAL CAVITY
}

\author{
A. M. ZEILLEMAKER, ${ }^{1}$ F. P. J. MUL, ${ }^{2}$ \\ A. A. G. M. HOYNCK VAN PAPENDRECHT, ${ }^{1}$ \\ P. LEGUIT, ${ }^{1}$ H. A. VERBRUGH ${ }^{3}$ and D. $\operatorname{ROOS}^{2}$ \\ ${ }^{1}$ Department of Surgery, Diakonessen Hospital, Utrecht, The Netherlands \\ ${ }^{2}$ Central Laboratory of the Netherlands Blood Transfusion Service and Laboratory \\ of Experimental and Clinical Immunology, University of Amsterdam, Amsterdam, \\ The Netherlands \\ ${ }^{3}$ Department of Medical Microbiology, Academic Hospital Rotterdam, Rotterdam, \\ The Netherlands
}

\begin{abstract}
We have investigated the role of human mesothelium in an in vitro model of peritonitis on the monocyte adherence to and migration across monolayers of peritoneal mesothelial cells. Monocytes adhere avidly to non-activated mesothelial cell monolayers; however, migration in this situation was minimal. Prestimulation of the monolayers with II- $1 \beta$ did not alter these results. Anti-CD18 and anti-VLA-4 mAbs used in combination had an additive inhibitory effect on monocytes adherence to resting or IL- $1 \beta$-pretreated mesothelial cells. MCP-1 and TGF- $\beta$ are secreted by mesothelial cells. Both have a modest role in mesothelium-induced monocyte chemotaxis: mAbs against these cytokines had an additive inhibitory effect on the chemotaxis induced by supernatant from $24-\mathrm{h}$ prestimulated mesothelial cells. Our results indicate that the mesothelium itself has a limited role in the influx of monocytes into the peritoneal cavity during the onset of peritonitis.
\end{abstract}

\section{INTRODUCTION}

As an initial event in acute bacterial peritonitis, a massive influx of neutrophils is observed into the peritoneal fluid, followed within 24 hours by the migration of large numbers of monocytes (1). Previous in vitro studies have shown that activated mesothelium stimulates the neutrophil influx by inducing neutrophil adherence (2) and by secreting cytokines (3-6). The latter process induces a rapid and strong migration of neutrophils across mesothelial cell monolayers 
(6). Monocyte migration across endothelial monolayers seems to occur much like the neutrophil transmigration, and requires also the interaction of specific adhesion surface molecules and locally produced cytokines $(3,7,8)$. The present study was designed to investigate the qualitative role of mesothelial adhesion receptors and mesothelial-derived cytokines in monocytes adherence to and migration across cultured monolayers of human mesothelial cells.

\section{MATERIALS AND METHODS}

Monoclonal Antibodies (mAbs). The following mAbs were used. mAb against E-Selectin (ENA2 [IgG 1 ) (9), VCAM-1 (4B9 [IgG 1$]$ ) (10), and ICAM-1 (RR1/1 [lgG 1$)(11)$, were used for immunofluorescence assays. The influence of the following mAbs was studied in the adherence and migration assay: CLB-LFA-1/1 $\left(\operatorname{IgG}_{1}\right)(12)$ against the common $\beta$ chain CD18 of the CD11/CD18 family of $\beta_{2}$ integrins and mAb HP1/3 (IgG $)$ against the $\alpha$ chain of VLA-4 (CD49d) (13). mAb against transforming growth factor- $\beta$ (TGF- $\beta$; R\&D systems, Minneapolis, Minnesota) and Ab against monocyte chemotactic protein-1 (MCP-1; polyclonal rabbit anti-human MCAF; Genzyme Corporation, Cambridge, Massachusetts) were used to study the influence of mesothelium-derived cytokines in the chemotaxis of monocytes in a modified Boyden chamber assay.

Mesothelial Cell Culture. Mesothelial cells (MC) were isolated from human omentum according to techniques modified from Nicholson et al. (14) and Wu et al. (15), as previously described (16). In brief, small pieces of omentum were removed early in the operative procedure from patients undergoing abdominal surgery for non-infectious conditions. All patients gave informed consent. The omentum was transferred to fluid containing $0.05 \%(w / v)$ trypsin $-0.02 \%(w / v)$ EDTA (Gibco, Life Technologies, Paisley, UK). After $15 \mathrm{~min}$. the detached MC were pelleted by centrifugation at $1200 \mathrm{rpm}$ for $5 \mathrm{~min}$. and resuspended in supplemented M-199 medium (Gibco). MC were grown until confluence in a $37^{\circ} \mathrm{C}$, fully humidified, $5 \% \mathrm{CO}_{2}$ cabinet in polystyrene culture flasks ( $75 \mathrm{~cm}^{2}$, Costar, Cambridge, Massachusetts) precoated with fibronectin. The identity of MC was demonstrated by the absence of von Willebrand factor staining (17) and the presence of intracellular cytokeratins by immunofluorescence with monoclonal antibodies (18) (Dakopatts, Glosstrup, Denmark).

Determination of Surface Antigen Expression. The expression of the adhesion molecules E-Selectin, ICAM-1 and VCAM-1 by mesothelial cells upon activation was measured by FACS analysis. MC were subcultured to confluent monolayers in 6-well culture dishes (Costar). The MC were activated by incubation with human recombinant interleukin-1 $\beta$ (IL-1 $\beta)(25 \mathrm{U} / \mathrm{ml}$; Genzyme Corporation) for various periods. A control well with $\mathrm{MC}$ was not incubated with IL-1 $\beta$. After activation, the MC were non-enzymatically detached by incubation with PBS/EDTA $(2 \mathrm{mM})$ for $15 \mathrm{~min}$. at $37^{\circ} \mathrm{C}$. MC in suspension were washed twice in ice-cold PBS and were subsequently incubated with the primary $\mathrm{mAbs}$ for $30 \mathrm{~min}$. at $4^{\circ} \mathrm{C}$. Thereafter, the cells were washed twice in ice-cold PBS, containing $0.5 \%$ (v/v) bovine serum albumin (BSA), and the procedure was repeated with FITC-labeled goat-anti-mouse-lg for another $30 \mathrm{~min}$. at $4^{\circ} \mathrm{C}$. After two washes, mAb binding was quantified for 10,000 cells with a FACScan (Becton Dickinson, Mountain View, California) and was expressed as mean fluorescence intensity (MFI).

Isolation of Monocytes. Blood was obtained from healthy volunteers and anticoagulated with $0.4 \%(\mathrm{w} / \mathrm{v})$ trisodium citrate ( $\mathrm{pH} 7.4)$. Monocytes were purified from buffy coats as described (19). In brief, blood cells were centrifuged over isotonic Percoll (specific gravity at room temperature, $\left.1.077 / \mathrm{cm}^{3}\right)$. The interphase, containing the mononuclear cells, was taken for isolation of the mono- 
cytes by countercurrent centrifugal elutriation (19). Purity of the monocytes was $\geq 95 \%$, and viability remained $\geq 95 \%$, as determined by lactate dehydrogenase (LDH) release (20).

Labeling of Monocytes. Freshly purified monocytes were radiolabeled with ${ }^{51} \mathrm{Cr}$ according to Gallin et al. (21) with minor modifications. Briefly, monocytes were incubated at $4^{\circ} \mathrm{C}$ for 15 min. with $0.5 \mu \mathrm{Ci}$ of ${ }^{51} \mathrm{Cr}$ per $10^{6}$ cells (sodium chromate, 200 to $500 \mathrm{Ci} / \mathrm{g}$; New England Nuclear, Boston, MA) in 50\% (v/v) M-199 (Gibco Life Technologies, Paisley, UK), 50\% (v/v) RPMI-1640 (Gibco), supplemented with $0.1 \%(\mathrm{v} / \mathrm{v}) \mathrm{HSA}$. The cells were subsequently washed and resuspended in incubation medium for cell suspensions, containing $20 \mathrm{mM}$ Hepes, $132 \mathrm{mM} \mathrm{NaCl}, 1 \mathrm{mM} \mathrm{MgSO}$, $1 \mathrm{mM} \mathrm{CaCl}_{2}, 6 \mathrm{mM} \mathrm{KCl}, 1.2 \mathrm{mM} \mathrm{KH}_{2} \mathrm{PO}_{4}, 5.5 \mathrm{mM}$ glucose and $0.5 \%$ (w/v) $\mathrm{HSA}, \mathrm{pH} 7.4$ at $4{ }^{\circ} \mathrm{C}$. Incubation of the monocytes took place for $30 \mathrm{~min}$., during which the temperature of the suspension was gradually increased to room temperature. Subsequently, the monocytes were washed twice and resuspended in $50 \%(\mathrm{v} / \mathrm{v}) \mathrm{M}-199,50 \%(\mathrm{v} / \mathrm{v}) \mathrm{RPMI}-1640,0.5 \%(\mathrm{v} / \mathrm{v}) \mathrm{HSA}$ at $37^{\circ} \mathrm{C}$. Aggregated cells were removed by cotton-wool filtration, and the remaining cells were resuspended in fresh incubation medium at a concentration of $10^{6} \mathrm{cells} / \mathrm{ml}$. Viability after labeling remained $\geq 95 \%$.

Migration Assay. Inverted filters (with MC 'hanging' on the filters) were used to study migration in the physiologically relevant direction (submesothelial tissue to peritoneal cavity), thus permitting the monocytes to adhere to the basolateral side of the MC monolayer. MC were subcultured to confluent monolayers on inverted polycarbonate membranes $(8.0 \mu \mathrm{m}$ pore size, 24.5 $\mathrm{mm}$ diam) of Transwell cell culture chamber inserts (Costar), according to Parkos et al. (22) with minor modifications, as previously described (6). MC monolayers reached confluence in five days as determined by phase-contrast microscopy, microscopy of May-Grünwald/Giemsa stained filters and by electrical resistance measurements (6). In some experiments the monolayers were preincubated with IL-1 $\beta(25 \mathrm{U} / \mathrm{ml})$ added to the lower compartment during 6 hours prior to adding the monocytes. IL- $1 \beta$ had no effect on the morphology of the cells, nor did it influence the electrical resistance of the monolayers (6). When indicated, formyl-leucyl-methionyl-phenylalanine (FMLP; Sigma Co., St. Louis, Missouri) was added to the lower compartment in a final concentration of $10^{-8} \mathrm{M}$. In all experiments the upper compartment of the cell culture chamber inserts was washed twice with $50 \%(\mathrm{v} / \mathrm{v}) \mathrm{M}-199,50 \%(\mathrm{v} / \mathrm{v})$ RPMI- $1640,0.5 \%(\mathrm{v} / \mathrm{v}) \mathrm{HSA}$ prewarmed to $37^{\circ} \mathrm{C}$ before adding the monocytes. The fluid in the lower compartment was not replaced. ${ }^{51} \mathrm{Cr}$-labeled monocytes $\left(10^{6}\right.$ cells $\left./ \mathrm{ml}\right)$ prewarmed to $37^{\circ} \mathrm{C}$ were added to the upper compartments. The chamber plates were incubated at $37^{\circ} \mathrm{C}$ in a $5 \% \mathrm{CO}_{2}$ incubator for $60 \mathrm{~min}$. After incubation, the fluid of each compartment was collected. The amount of radioactivity present in the fluids as well as that of the filter, removed from its cylindric container, were determined in a gammacounter. Recovery was always $\geq 92 \%$. The radioactivity measured in the filter was taken to represent monocyte adhesion. The extent of migration was calculated from the radioactivity found in the fluid of the lower compartment. The results were expressed as percentages of the total radioactivity, i.e. monocytes, added to the chambers.

Measurement of Chemotaxis. The Boyden chamber (48-well chemotaxis chamber; Neuro Probe Inc., Cabin John, Maryland) was used for measurement of monocyte chemotaxis. The Boyden chamber contained a $8.0-\mu \mathrm{m}$ migration filter on top of a $0.45-\mu \mathrm{m}$ stopping filter. Chemotactic stimulus, added to the lower compartment of the Boyden chamber, consisted of mesothelial cell supernatant. These supernatants were obtained from non-stimulated or rIL-1 $\beta$-prestimulated mesothelial cells monolayers, cultured on 6-well plates (Costar) during 6 or 24 hours. Culture medium (supplemented M-199) and FMLP $\left(10^{-8} \mathrm{M}\right.$; Sigma Co.) diluted in culture medium were used as negative and positive controls, respectively. When indicated, mAb against MCP-1 or Ab against TGF- $\beta$ was added to the supernatant as well as to the monocytes 10 min. prior to adding the monocytes. Monocytes were suspended in incubation medium for cell suspensions, as described earlier, supplemented with heparin $(10 \mathrm{IU} / \mathrm{ml}) .10^{5}$ monocytes were added to the upper compartment of the Boyden chamber and incubated for 2.5 hours. Thereafter, the $8.0-\mu \mathrm{m}$ Boyden chamber filters 
were moved, fixed in butanol/ethanol $(20 / 80 \%, v / v)$ for $10 \mathrm{~min}$. and stained with Weigert solution $(1 \% \mathrm{v} / \mathrm{v})$, i.e. hematoxylin in ethanol mixed with a $70 \mathrm{mM}$ acidic $\mathrm{FeCl}_{3}$ solution at a $1: 1$ ratio. The filters were dehydrated with ethanol, made transparent with xylol and fixed upside down. The chemotactic response of the monocytes were quantified with an image analyzer (Quantimet $570 \mathrm{C}$, Leica Cambridge Ltd., Cambridge, UK) using Quantimet 570 Control Software (QUIC, version 2.02) and a custom made software program written in $Q$ Basic (23). An automated microscope was used to step through the filters at a given number of levels in the $\mathrm{Z}$ direction with a certain $\mathrm{Z}$ level interval. Cells were counted at each of these levels. Chemotaxis was expressed as the mean monocyte migration distance into the filter in $\mu \mathrm{m}$ from the surface of the filter.

\section{RESULTS}

Adhesion Receptors. ICAM-1 and VCAM-1 are present on the surface of non-activated $\mathrm{MC}$ in significant numbers (Table 1). After activation of the MC with IL- $1 \beta$, the expression of both adhesion proteins increased with a maximum expression for both proteins on the cell membrane after 6 to $8 \mathrm{~h}$. Thereafter, the expression of ICAM-1 and VCAM-1 gradually decreased, but remained above background after $24 \mathrm{hrs}$ and even after $48 \mathrm{hrs}$ (Table 1). Activation of the MC with TNF- $\alpha$ instead of IL- $1 \beta$ showed similar increases in ICAM- 1 and VCAM-1 expression, with the same kinetic profile (data not shown). E-Selectin was not detectable on either resting or activated MC: binding of anti-E-Selectin mAb never exceeded levels with control mAbs (Table 1).

Monocyte Adherence and Migration. Monocytes adhered avidly to nonactivated MC monolayers. However, migration in this situation was minimal

Table 1. Surface Antigen Expression of Adhesion Molecules on Mesothelial Cells at Various Times After IL-1 $\beta$ Addition ${ }^{a}$

\begin{tabular}{cccc}
\hline $\begin{array}{c}\text { Time after } \\
\text { IL- } 1 \beta \text { induction } \\
\text { (hrs) }\end{array}$ & E-Selectin & ICAM-1 & VCAM-1 \\
\hline 0 & $9 \pm 6$ & $2156 \pm 465$ & $584 \pm 121$ \\
2 & $11 \pm 8$ & $2620 \pm 559$ & $828 \pm 163^{b}$ \\
4 & $12 \pm 7$ & $3056 \pm 681^{b}$ & $821 \pm 183^{b}$ \\
6 & $11 \pm 9$ & $3416 \pm 492^{c}$ & $1029 \pm 237^{b}$ \\
8 & $29 \pm 16$ & $3444 \pm 638^{c}$ & $1082 \pm 306$ \\
16 & $17 \pm 8$ & $2996 \pm 333^{c}$ & $874 \pm 234$ \\
24 & $20 \pm 13$ & $2950 \pm 508^{c}$ & $722 \pm 149^{b}$ \\
48 & $11 \pm 7$ & $2414 \pm 485^{b}$ & $787 \pm 196$ \\
\hline
\end{tabular}

\footnotetext{
${ }^{a}$ Results are expressed as mean fluorescence intensity (MFI) $\pm S E M$ of 5 separate experiments. ${ }^{b} p \leq 0.05$.

${ }^{c} p \leq 0.01$, significant increase in membrane expression compared to non-stimulated mesothelial cells (paired $t$-test).
} 


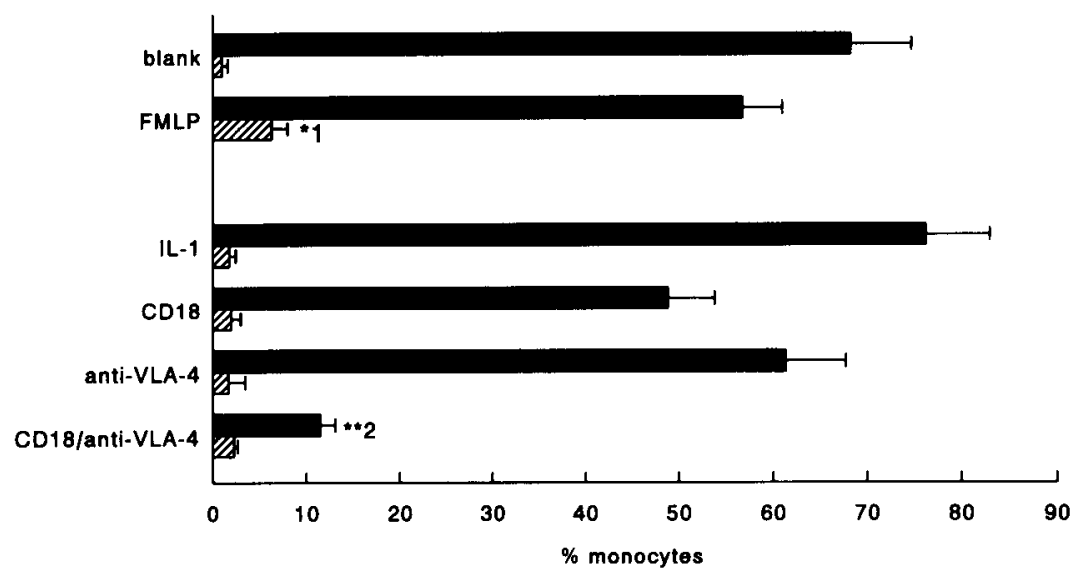

Fig. 1. Monocyte adherence to and migration across inverted monolayers of MC. Mesothelial cells were cultured on inverted $8.0 \mu \mathrm{m}$ filters, and monocyte adherence and migration were measured 60 min after addition of the monocytes. Blank represents adherence to and migration across resting MC. Effects of mAbs against CD18 and VLA-4 on IL-1 $\beta$ induced monocyte adhesion to and migration across inverted MC monolayers are shown. Black bars represent monocyte adherence to, and shaded bars represent monocyte migration across MC monolayers. Results are expressed as the mean $\pm S E M$ of three separate experiments. Monocyte migration was significantly increased compared to migration across non-activated MC monolayers. Adhesion of monocytes to invested MC monolayers was significantly decreased compared to adhesion to IL- $1 \beta$-activated MC monolayers (paired $t$-test). ${ }^{*} p \leq 0.05,{ }^{* *} p \leq 0.01$.

(Figure 1). Activation of the MC monolyers with IL-1 $\beta$ for $6 \mathrm{~h}$ showed little modulating effect: the adherence of monocytes to $\mathrm{MC}$ monolayers increased marginally, but still only very small numbers of monocytes transmigrated across the MC monolayers (Figure 1).

CD18 mAb CLB LFA1/1 had little effect on monocyte adherence to cytokine-activated MC monolayers. The same effect was seen after incubation of the monocytes with anti-VLA-4 mAb HP1/3. However, CD18 and anti-VLA$4 \mathrm{mAbs}$ used in combination had a synergistic inhibitory effect on monocyte adherence to IL-1 $\beta$-pretreated cells ( $85 \%$ inhibition, $p \leq 0.01$ ) (Figure 1). The same inhibitory effect of this combination of mAbs was observed when monocyte adherence to non-stimulated MC monolayers was measured (data not shown). FMLP added to the lower compartment of the Transwell system induced a small but significant increase in migration of the monocytes across non-stimulated MC monolayers $(p \leq 0.05)$ (Figure 1).

Chemotaxis of Mesothelial Supernatant. The mean migration distance of monocytes towards fresh culture medium in Boyden chambers was minimal (Figure 2). In contrast, MC supernatant induced a significantly increased mono- 




Fig. 2. Chemotaxis of monocytes in Boyden chambers $(2.5 \mathrm{hrs})$ induced by supernatant from nonactivated, and from $6 \mathrm{~h}$ or $24 \mathrm{hrs}$ IL-1 $\beta$ pretreated mesothelial cell monolayers. The monocyte chemotaxis measured towards culture medium and towards FMLP were used as negative and positive controls, respectively. The chemotactic response was quantified with an image analyzer, as described in the Material and Methods section. Cells were counted at small levels spread $10 \mu \mathrm{m}$ apart throughout the whole filter $(150 \mu \mathrm{m})$. Results are expressed as the mean migration distance $\pm S E M$ of three separate experiments. Mean migration distance was significantly higher than the distance towards (culture) medium. Mean migration distance was significantly lower than the distance induced by supernatant from MC monolayers prestimulated during $24 \mathrm{~h}$ with IL- $1 \beta$ (paired $t$-test). ${ }^{*} p \leq 0.05$, ${ }^{* *} p \leq 0.01$.

cyte chemotaxis, comparable to levels induced by FMLP ( $p \leq 0.05$ ) (Figure 2 ). Changes in the 'activity-state' of the MC played a minor role, because activation of the MC monolayers with IL-1 $\beta$, even for $24 \mathrm{hrs,} \mathrm{did} \mathrm{not} \mathrm{have} \mathrm{a}$ stimulating effect on the chemotaxis of the monocytes towards the culture medium (Figure 2).

Anti-MCP-1 Ab had an inhibitory effect on the chemotaxis of mesothelial cell-derived supernatant, but this effect was only significant in supernatant of 24 hrs IL-1 $\beta$ prestimulated MC monolayers ( $p \leq 0.05$ ) (Figure 2). AntiTGF- $\beta \mathrm{Ab}$ had a minor effect on supernatant from non-stimulated MC cells, but a significant reducing effect on supernatant obtained from $24 \mathrm{hrs}$ IL-1 $\beta$ activated MC monolayers ( $p \leq 0.05$ ) (Figure 2). Furthermore, anti-MCP-1 and anti-TGF- $\beta$ used in combination had a synergistic inhibitory effect on the monocyte chemotaxis ( $p \leq 0.01$ ) (Figure 2 ), to levels comparable to the migration distance measured towards fresh culture medium. Chemotaxis induced by FMLP was not influenced by Abs against MCP-1 or TGF- $\beta$ (data not shown). 


\section{DISCUSSION}

Adherence to and migration across activated endothelial cell monolayers is a process that involves adhesion receptors on both types of cells and depends on locally produced cytokines $(3,7,8)$. In peritonitis, monocytes have to transmigrate not only across an endothelial cell barrier but also across a mesothelial cell monolayer before they an enter the abdominal cavity. Previous studies on the role of mesothelium in this process have been performed by Gerwin et al. (5) who described the presence of mRNA for TGF- $\beta$ in MC, a chemoattractant for PMN and monocytes. Jonić et al. (3) detected mRNA expression for MCP-1 in activated MC and also described the presence of ICAM-1 and VCAM-1 on MC monolayers. In our study we described the qualitative role of adhesion receptors in monocyte adherence to and the lack of importance of some $\mathrm{MC}$ derived cytokines in monocyte migration across MC monolayers.

Adherence of monocytes to $\mathrm{MC}$ is, like adherence of monocytes to endothelial cells (7), a combined CD18/ICAM-1 and VLA-4/VCAM-1 dependent process. E-Selectin is not expressed on the membrane of MC monolayers and, therefore, plays no role in monocyte adherence. No alteration in the level of adhesion was found even when monocyte adherence was measured $6 \mathrm{hrs}$ after activation with IL- $1 \beta$, at the time of maximal expression of both VCAM- 1 and ICAM-1. In a previous study (2) we reported that an increase in ICAM-1 expression on the MC membrane itself was insufficient for neutrophil adherence. 'Slow travelling' of monocytes in our system with Transwell filters resulted in minimal monocyte transmigration across activated MC monolayers. In contrast, PMN are able to transmigrate rapidly under the same conditions ( $23 \%$ in $30 \mathrm{~min}$.) (2); however, PMN were not able to adhere to transmigrate across non-activated MC monolayers as do monocytes (2). Thus, activation of the MC monolayer modulates to a large extent the PMN adherence to and migration across these cell layers, but has little influence on monocytes adherence and migration.

Boyden chamber experiments with supernatant of $24 \mathrm{hrs}$ IL- $1 \beta$ prestimulated MC showed that its chemotactic activity was inhibited by adding Abs against MCP-1 and TGF- $\beta$. This inhibition supports a role for these monocyte chemoattractants in monocyte recruitment towards the abdominal cavity during peritonitis. However, significant monocyte chemotaxis was also measured in the Boyden chamber towards supernatant from non-activated MC. This finding concurs with the in vivo situation that during continuous ambulatory peritoneal dialysis (CAPD) a population of resident macrophages of monocytic origin is found in the peritoneal effluent even in the absence of inflammation, i.e. without the presence of neutrophils $(24,25)$. In the event of peritonitis, circulating monocytes from outside the peritoneal cavity will be attracted to the site of 
inflammation by chemotaxis $(26,27)$, preceded by a massive influx of neutrophilic granulocytes $(8,28)$.

From the data presented in this study it is concluded that, in contrast to PMN migration, the mesothelium itself has little modulating effect on the process of transmesothelial cell migration of monocytes which takes place in the inflammatory response during bacterial peritonitis.

Acknowledgments - The authors thank Dr. Leo Koenderman and Dr. Jan van der Linden of the department of Pulmonary Diseases, University Hospital Utrecht, The Netherlands, for the availability of the Quantimet $570 \mathrm{C}$ image analyzer. This study was supported by the Dutch Kidney Foundation Grant No. 92.1265.

\section{REFERENCES}

1. Puntis, M. 1989. Peritoneal defence mechanisms. In The Peritoneum and Peritoneal Access. S. Bengmark, editor. Wright, London. 74-84.

2. Zeillemaker. A. M., F. P. J. Mul, A. A. G. M. Hoynck van Papendrecht, P. Leguit, H. A. VerBRUGH, and D. Roos. 1995. Neutrophil adherence to and migration across monolayers of human peritoneal mesothelial cells. (Manuscript submitted for publication.)

3. Jonjić, N., G. Peri, S. Bernasconi, F. L. Scacca, F. Colotta, P. Pelicci, L. Lanfrancone, and A. Montovani. 1992. Expression of adhesion molecules and chemotactic cytokines in cultured human mesothelial cells. J. Exp. Med. 176:1165-1174.

4. Topley, N., Z. Brown, A. Jörres, J. Westwick, M. Davies, G. A. Coles, and J. D. Williams. 1993. Human peritoneal cells synthesize interleukin-8. Am. J. Path. 142:18761886.

5. Gerwin, B. I., J. F. Lechner, R. R. Reddel A. B. Roberts, K. C. Robbins, E. W. GabrielSON, and C. C. HaRRIs. 1987. Comparison of production of transforming growth factor $\beta$ and platelet derived growth factor by normal human mesothelial cells and mesothelioma cell lines. Cancer Res. 47:6180-6184.

6. Zeillemaker, A. M., F. P. J. Mul, A. A. G. M. Hoynck van Papendrecht, T. W. Kuipers, D. Roos, P. Leguit, and H. A. Verbrugh. 1995. Polarized secretion of interleukin-8 by human mesothelial cells: a role in neutrophil migration. Immunology 84:227-232.

7. Hakkert, B. C., T. W. Kuijpers, J. F. M. Leeuwenberg, J. A. van Mourik, and D. Roos. 1991. Neutrophil and monocyte adherence to and migration across monolayers of cytokineactivated endothelial cell: the contribution of CD18, ELAM-1, and VLA-4, Blood 78:27212726.

8. Kuijpers, T. W., and J. M. Harlan. 1993. Monocyte-endothelial interactions: insights and questions. J. Lab. Clin. Med. 112:641-651.

9. Leeuwenberg, J. F. M., T. M. A. A. Jeunhomme, and W. A. Buurman. 1990. Adhesion of polymorphonuclear cells to human endothelial cells. Adhesion-molecule-dependent, and Fc receptor-mediated adhesion-molecule-independent mechanisms. Clin. Exp. Immunol. 81:496500.

10. Carlos, T. M., B. R. Schwartz, N. L. Kovach, E. Yee, M. Rosso, L. Osborn, B. Newman, R. LOBB, and J. M. HARLAN. 1990. Vascular cell adhesion molecule-1 mediates lymphocyte adherence to cytokine activated cultured endothelial cells. Blood 76:965-970. 
11. Rothlein, R., M. L. Dustin, S. D. Marlin, and T. A. Springer. 1986. A human intercellular adhesion molecule (ICAM-1) distinct from LFA-1. J. Immunol. 137:1270-1274.

12. Miedema, F., P. A. T. Tetteroo, W. G. Hesselink, G. Werner, H. Spits, and C. J. M. MELIEF. 1984. Both Fc-receptors and lymphocyte-function-associated antigen-1 on human $T$ lymphocytes are required for antibody-dependent cellular cytotoxicity (killer cell activity). Eur. J. Immunol. 14:518-525.

13. Elices, M. J., L. Osborn, Y. Takada, C. Crouse, S. Luhowskyu, M. E. Hemler, and R. R. LOBB. 1990. VCAM-1 on activated endothelium interacts with the leucocyte integrin VLA-4 at a site distinct from the VLA-4/fibronectin binding site. Cell 60:577-584.

14. Nicholson, L. J., J. M. F. Clarke, R. M. Pittilo, S. J. Machin, and N. Woolf. 1984. The mesothelial cell as a non-thrombotic surface. Thromb. Haemostas. 37:108-112.

15. Wu, Y. J., L. M. Parker, N. E. Binder, M. A. Beckett, J. H. Sinard, C. T. Griffiths, and J. G. RHEINWALD. 1982. The mesothelial keratins: A new family of cytoskeletal proteins identified in cultured mesothelial cells and nonkeratizing epithelia. Cell 31:693-703.

16. Zeillemaker, A. M., H. A. Verbrugh, A. A. G. M. Hoynck van Papendrecht, and P. Leguit. 1994. CA 125 secretion by peritoneal mesothelial cells. J. Clin. Path. 47:263-265.

17. Pronk, A., P. G. de Groot, A. A. G. M. Hoynck van Papendrecht, H. A. Verbrugh, P. Leguit, Th. J. M. V. van VRoOnhoven, and J. J. Sixma. 1992. Thrombogenicity and procoagulant activity of human mesothelial cells. Arterioscler. Thromb. 12:1428-1436.

18. Connell, N. D., and J. G. Rheinwald. 1983. Regulation of the cytoskeleton in mesothelial cells: Reversible loss of keratin and increase in vimentin during rapid growth in culture. Cell 34:245-253.

19. Roos, D., and M. DE BOER. 1986. Purification and cryopreservation of phagocytes from human blood. Methods Enzymol. 132:225-245.

20. Hakkert, B. C., J. M. Rentenaar, W. G. van Aken, D. Roos, and J. A. van Mourik. 1990. A three-dimensional model system to study the interactions between human leucocytes and endothelial cells. Eur. J. Immunol. 20:2775-2781.

21. Gallin, J. I., R. A. ClarK, and H. R. Kimball. 1973. Granulocyte chemotaxis: an improved in vitro assay employing ${ }^{51} \mathrm{Cr}$-labeled granulocytes. J. Immunol. 110:233-228.

22. Parkos, C. A., C. Delp, M. A. Arnaout, and J. Madara. 1991. Neutrophil migration across a cultured intestinal epithelium. J. Clin. Invest. 88:1605-1612.

23. Pieters, W. R., L. A. M. J. Houben, L. Koenderman, and J. A. M. Raaijmakers. 1995. C5a-Induced migration of human monocytes is primed by dexamethasone. Am. J. Respir. Cell. Mol. Biol. (in press.)

24. Parwaresch, M. R., H. J. Radzun, and M. Dommes. 1981. The homogeneity and monocytic origin of human peritoneal macrophages evidenced by comparison of esterase polymorphism. Am. J. Path. 102:209-218.

25. Radzun, H. J., M. Dommes, M. Henselmans, and M. R. Parwaresch. 1982. Resident human peritoneal macrophages. A monocytic cell line. Acta Cytol. 26:363-366.

26. VolKman, A. 1966. The origin and turnover of mononuclear cells in peritoneal exudates in rats. J. Exp. Med. 124:241-254.

27. Cichocki, T., Z. Hanicki, W. Sulowicz, O. Smolenski, J. Kopec, and M. Zembala. 1983. Output of peritoneal cells into peritoneal dialysate. Nephron 35:175-182.

28. Issekutz, T. B., A. C. Issekutz, and H. Z. Movat. 1981. The in vivo quantitation and kinetics of monocyte migration into acute inflammatory tissue. Am. J. Pathol. 103:47-54. 